9 Maisel AS, McCord J, Nowak RM, Hollander JE et al. Bedside B-Type natriuretic peptide in the emergency diagnosis of heart failure with reduced or preserved ejection fraction. Results from the Breathing Not Properly Multinational Study. J Am Coll Cardiol 2003;41:2010-7.

10 Cowie MR, Struthers AD, Wood DA, Coats $\mathrm{AJ}$ et al. Value of natriuretic peptides in assessment of patients with possible new heart failure in primary care. Lancet 1997;350:1349-53.

11 Cowie MR, Jourdain P, Maisel A, Dahlstrom $\mathrm{U}$ et al. Clinical applications of B-type natriuretic peptide (BNP) testing. Review. Eur Heart J 2003;24:1710-8.

12 Royal College of Physicians. Chronic heart failure: national clinical guideline for diagnosis and management in primary and secondary care (full version of NICE Guideline, developed by the National Collaborating Centre for Chronic Conditions). Appendix G: a cost-effectiveness model for the appropriate use of echocardiography in the diagnosis of heart failure. London: RCP, 2003.

13 Cleland JG, Swedberg K, Follath F, Komajda $\mathrm{M}$ et al. The EuroHeart Failure survey programme - a survey on the quality of care among patients with heart failure in Europe. Part 1: patient characteristics and diagnosis. Eur Heart J 2003;24:442-63.

14 Cleland JG, Freemantle N, Ball SG, Bonser $\mathrm{RS}$ et al. The heart failure revascularisation trial (HEART): rationale, design and methodology. Review. Eur J Heart Fail 2003; 5:295-303.

\title{
The treatment of chronic heart failure
}

due to left ventricular systolic dysfunction

R S Gardner MB ChB MRCP,

Specialist Registrar in Cardiology/GIM,

Monklands Hospital, Airdrie

TA McDonagh MB ChB MD FRCP,

Senior Lecturer in Cardiology, Glasgow Royal Infirmary, Glasgow

Clin Med 2004;4:18-22

It is of paramount importance to realise that the best way to treat chronic heart failure (CHF) is to prevent it happening in the first place by modifying known risk factors for ischaemic heart disease (IHD) and better treatment of myocardial infarction (MI). An aetiology should always be sought for CHF as its reversal may subsequently improve cardiac function. Once established, CHF has a poor prognosis - worse than many forms of cancer. Treatment aims are to reduce mortality and relieve symptoms. It is encouraging that recent improvements in disease-modifying therapy have markedly improved both morbidity and mortality.

\section{Disease-modifying therapy}

\section{Angiotensin-converting enzyme inhibitors}

Angiotensin-converting enzyme inhibitors (ACEIs) are the first-line drugs which should be given to all patients with left ventricular systolic dysfunction (LVSD) whether symptomatic $^{1,2}$ or not, ${ }^{3}$ combined with a diuretic if there is evidence of cardiac decompensation (eg peripheral or pulmonary oedema) (Fig 1). These drugs reduced both morbidity and mortality in clinical trials involving more than 7,000 patients (on average, a $20-25 \%$ relative risk (RR) reduction). Unless there is a contraindication, such as significant renal disease, angioedema or ACEI-induced cough, their use is mandatory.

\section{Beta-blockers}

There is also now unequivocal evidence that the beta-blockers bisoprolol, ${ }^{4}$ carvedilol $^{5-9}$ and metoprolol ${ }^{10}$ reduce mortality and long-term symptoms in patients with all grades of CHF and in post-MI LVSD. Their use is imperative in patients who are free of cardiac decompensation and should be uptitrated slowly - 'start low, go slow'. Neither chronic obstructive airways disease without airways reversibility nor mild to moderate peripheral vascular disease should be seen as a contraindication to beta-blocker therapy.

\section{Aldosterone antagonists}

Spironolactone reduces mortality and morbidity in patients with moderate to severe CHF (New York Heart Association (NYHA) classes III and IV) when used in

TRIAL ACRONYMS

$\begin{array}{ll}\text { CARE-HF } & \begin{array}{l}\text { Cardiac Resynchronisation in Heart Failure (European study) } \\ \text { CHARM }\end{array} \\ \begin{array}{l}\text { Candesartan in Heart Failure: Assessment of Reduction } \\ \text { in Mortality and Morbidity }\end{array} \\ \text { COMPANION } & \begin{array}{l}\text { Comparison of Medical Therapy, Pacing, and Defibrillation } \\ \text { in Chronic Heart Failure }\end{array} \\ \text { DIG } & \text { Digitalis Investigation Group } \\ \text { WASH } & \text { Warfarin-Aspirin Study in Heart Failure } \\ \text { WATCH } & \text { Warfarin Antiplatelet Therapy in Chronic Heart Failure }\end{array}$


addition to standard therapy (ACEI and beta-blocker). ${ }^{11}$ Eplerenone has similar effects in post-MI LVSD. ${ }^{12}$

Caution: these drugs can impair renal function and cause significant hyperkalaemia.

\section{Angiotensin II receptor antagonists}

Angiotensin II receptor antagonists are an effective alternative in truly ACE intolerant individuals, although ACEIs should always be regarded as the first-line drugs of choice. In the recent CHARM study (see end of text for trial acronyms), the addition of candesartan to existing triple therapy (ACEI (100\% of patients), beta-blocker (55\% of patients) and spironolactone (17\% of patients)) reduced cardiovascular death and hospitalisation for CHF by $15 \%{ }^{13}$ This trial suggests that patients remaining symptomatic despite ACEI and beta-blocker may now have another therapeutic option.

\section{Hydralazine and nitrates}

Hydralazine and nitrates can also be considered in patients intolerant to both ACEIs and angiotensin-receptor antagonists. ${ }^{14,15}$

\section{Symptomatic therapy}

\section{Diuretics}

Diuretics still have an important place in the management of both the symptoms and signs of fluid retention in CHF. Diuretics have not been shown to lower mortality - indeed, higher doses are associated with a poorer outcome. ${ }^{16,17}$ Therefore, the dose of diuretic should be as low as possible, with fluid restriction as necessary. Usually a loop diuretic, such as frusemide or bumetanide is necessary. Once doses of, for example, $80 \mathrm{mg}$ frusemide bd are reached, sequential nephron blockade with a thiazide diuretic (eg bendrofluazide or metolazone) may relieve signs of fluid retention with greater efficacy than further increases in the dose of loop diuretic. Renal function should be monitored closely and hypokalaemia corrected.

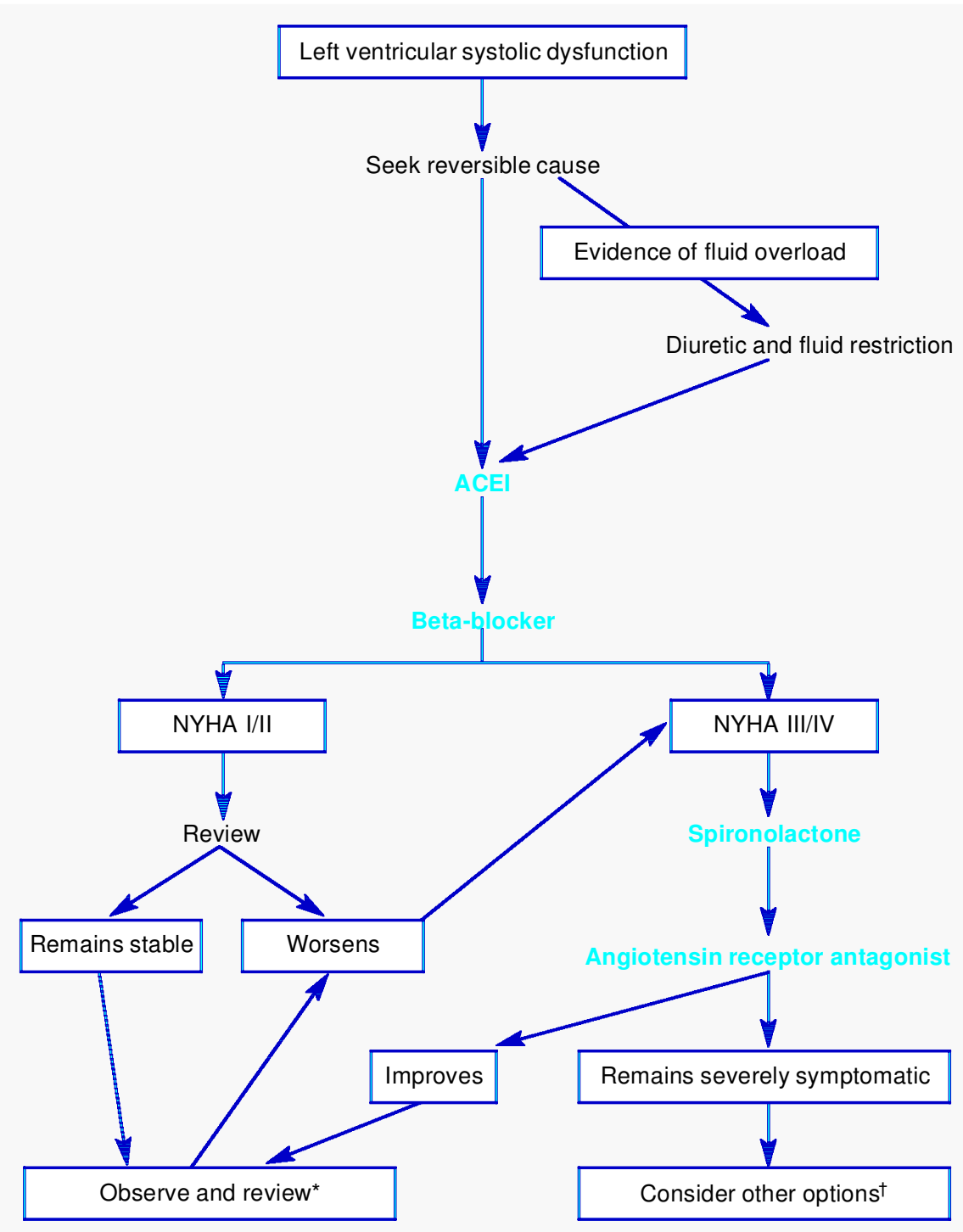

Fig 1. Algorithm for the management of left ventricular systolic dysfunction (ACEI = angiotensin-converting enzyme inhibitor; NYHA = New York Heart Association). ${ }^{*}$ Review process: symptoms, signs, weight, urea and electrolytes. Can disease-modifying therapy be optimised, can diuretics be reduced? ${ }^{\dagger}$ Consider: digoxin, increasing diuretic if evidence of cardiac decompensation, biventricular pacing, cardiac transplantation, anticoagulation in atrial fibrillation, left ventricular thrombus.

\section{Digoxin}

The role of digoxin appears less clear. The current recommendations (not based on evidence) are to introduce this drug in patients who remain symptomatic despite maximal medical therapy or to provide rate control for patients with atrial fibrillation (AF). Patients with AF were excluded in large digoxin studies, ${ }^{18,19}$ and the death rate was unaltered. Indeed, post-hoc analyses of the DIG trial have shown that more women died when they took digoxin than those who did not. ${ }^{20}$ In another study, men with serum digoxin concentrations above $1.2 \mathrm{ng} / \mathrm{ml}$ had a higher mortality than patients receiving placebo. ${ }^{21}$ Digoxin is best reserved for patients who remain markedly symptomatic, with large hearts and frequent hospitalisations. It should be avoided in those with ventricular arrhythmias.

\section{Other pharmacological therapy}

Patients with IHD should be on aspirin unless there is a specific contraindica- 
tion. The benefits of warfarin therapy in CHF are currently uncertain, except in patients with AF or known LV thrombus. This is the subject of two large clinical trials in CHF (WATCH and WASH).

Statin therapy is of benefit in both primary and secondary prevention in IHD, but its safety in CHF is still being investigated. Statins may lower mortality in non-ischaemic NYHA III/IV CHF (RR $=0.35$; confidence interval $=0.13-0.96$; $p=0.042) .^{22}$

Long-term use of high-dose allopurinol may lower mortality, possibly by negating the adverse effect of an elevated blood urate concentration. ${ }^{23}$ Clinical trials to address this question are ongoing.

Anaemia is common in CHF and is an independent predictor of mortality. ${ }^{24}$ Initial reports have demonstrated that treating patients with moderate/severe CHF with erythropoietin and intravenous iron improves their cardiac func- tion and reduces their need for hospital admission. ${ }^{25}$

It is important to avoid drugs that may exacerbate $\mathrm{CHF}$, for example nonsteroidal anti-inflammatory drugs, rate-limiting calcium antagonists (diltiazem and verapamil), class I anti-arrhythmic drugs, steroids and tricyclic antidepressants.

\section{Non-pharmacological intervention and lifestyle modification}

Lifestyle modifications should be encouraged, for example stopping smoking and alcohol, ${ }^{26}$ losing excess weight and taking regular aerobic exercise. $^{27}$ Annual immunisation for influenza and pneumococcus is recommended. ${ }^{28}$ Fluid intake should be restricted to 1.5-2 litres/day and patients counselled on the importance of monitoring their fluid balance (eg daily

\section{Key Points}

Following a diagnosis of chronic heart failure, an aetiology should be sought and any reversible cause treated

All patients with left ventricular systolic dysfunction should be started on an angiotensin-converting enzyme inhibitor (ACEI) and, when euvolaemic, a beta-blocker (except in the presence of true absolute contraindications)

With beta-blockers, 'start low, go slow'

If hypotension is a problem, it is better to be on a small dose of ACEI and beta-blocker than a large dose of either

Patients in New York Heart Association classes III and IV also benefit from spironolactone and may benefit from an angiotensin II receptor antagonist

Fluid balance is important - what goes in, must come out! Fluid and salt should be restricted and the smallest effective dose of diuretic used

Encourage patients to take responsibility for their condition: daily weights and lifestyle modification

Review patients - they can get better as well as worse. Has the correct aetiology/diagnosis been made? Is there another explanation for worsening breathlessness? Established patients not on an ACEI/beta-blocker may not truly be intolerant to these drugs

New therapeutic options are becoming available, including biventricular pacing, implantable cardioverter defibrillators and left ventricular assist devices

Cardiac transplantation remains an option for those patients who fail to improve or worsen despite maximum disease-modifying therapy

KEY WORDS: CPD, ACE inhibitors, beta-blockers, chronic heart failure, CPD, left ventricular systolic dysfunction (LVSD), treatment

weights). Salt rich foods should be avoided.

\section{Device therapy}

\section{Implantable cardioverter defibrillators}

Patients with LVSD secondary to IHD with an LV ejection fraction below 35\% benefit in terms of mortality reduction from implantable cardioverter defibrillators (ICD). ${ }^{29}$ Currently, ICDs are implanted into patients with IHD and LVSD with ventricular arrhythmia, but implementing these results in all patients with LVSD has huge cost implications.

\section{Cardiac resynchronisation therapy}

Cardiac resynchronisation therapy (CRT) is the subject of much research in CHF. In combination with stable, optimal medical therapy, CRT may improve patient well-being by correcting ventricular dysynchrony. This is achieved by the insertion of pacing leads into the right atrium and right ventricle as per a standard dual chamber (DDD) pacemaker, but also by pacing the left ventricle via a lead placed in the coronary sinus.

CRT improves symptoms and haemodynamics, reduces hospitalisations and increases effort capacity in patients in NYHA classes III/IV with wide QRS complexes. Its effects on mortality are being studied in the CARE-HF trial. ${ }^{30}$ Combined CRT/ICD implantation reduces mortality in $\mathrm{CHF}$ (COMPANION Trial). ${ }^{31}$ The place of CRT alone in CHF remains to be determined.

\section{Left ventricular assist devices}

Left ventricular assist devices (LVADs) are blood pumps that take over part of the heart's pumping function when implanted alongside or within the heart. LVADs are also now emerging as treatment options in advanced heart failure either as a bridge to transplantation or to recovery, or as destination therapy (for patients with end-stage heart failure who require permanent mechanical heart support and are not suitable for cardiac transplantation $).{ }^{32}$ 


\section{Surgical options}

In patients who fail to respond to medical or device therapy, surgical options include:

- revascularisation for hibernating myocardium

- ventricular remodelling (less commonly performed now), and

- cardiac transplantation.

\section{Cardiac transplantation}

Although donor organ availability restricts its use, cardiac transplantation remains an option for those patients with advanced heart failure who fail to respond to medical therapy. It carries a one-year mortality of around 19\% and an average life expectancy of 10 years. ${ }^{33}$ Although patients must have severe LVSD to warrant this procedure, they must otherwise be well because of the impact of major surgery and the significant side effects of the immunosuppressive regimen.

\section{References}

1 Effect of enalapril on survival in patients with reduced left ventricular ejection fractions and congestive heart failure. The SOLVD Investigators. N Engl J Med 1991; 325:293-302.

2 Effects of enalapril on mortality in severe congestive heart failure. Results of the Cooperative North Scandinavian Enalapril Survival Study (CONSENSUS). The CONSENSUS Trial Study Group. N Engl J Med 1987;316:1429-35.

3 Effect of enalapril on mortality and the development of heart failure in asymptomatic patients with reduced left ventricular ejection fractions. The SOLVD Investigators. $N$ Engl J Med 1992;327: 685-91. Erratum: N Engl J Med 1992;327: 1768.

4 The Cardiac Insufficiency Bisoprolol Study II (CIBIS-II): a randomised trial. Lancet 1999;353:9-13.

5 Packer M, Coats AJ, Fowler MB, Katus HA et al. Effect of carvedilol on survival in severe chronic heart failure. $N$ Engl J Med 2001;344:1651-8.

6 Packer M, Bristow MR, Cohn JN, Colucci WS et al. The effect of carvedilol on morbidity and mortality in patients with chronic heart failure. U.S. Carvedilol Heart Failure Study Group. N Engl J Med 1996; 334:1349-55.

7 Olsen SL, Gilbert EM, Renlund DG, Taylor
DO et al. Carvedilol improves left ventricular function and symptoms in chronic heart failure: a double-blind randomized study. J Am Coll Cardiol 1995;25:1225-31.

8 Effects of carvedilol, a vasodilatorbeta-blocker, in patients with congestive heart failure due to ischemic heart disease. Australia-New Zealand Heart Failure Research Collaborative Group. Circulation 1995;92:212-8.

9 Bristow MR, Gilbert EM, Abraham WT, Adams KF et al. Carvedilol produces dose-related improvements in left ventricular function and survival in subjects with chronic heart failure. MOCHA Investigators. Circulation 1996;94:2807-16.

10 Effect of metoprolol CR/XL in chronic heart failure: Metoprolol CR/XL Randomised Intervention Trial in Congestive Heart Failure (MERIT-HF). Lancet 1999;353: 2001-7.

11 Pitt B, Zannad F, Remme WJ, Cody R et al. The effect of spironolactone on morbidity and mortality in patients with severe heart failure. Randomized Aldactone Evaluation Study Investigators. N Engl J Med 1999; 341:709-17.

12 Pitt B, Remme W, Zannad F, Neaton J et al. Eplerenone Post-Acute Myocardial Infarction Heart Failure Efficacy and Survival Study Investigators. Eplerenone, a selective aldosterone blocker, in patients with left ventricular dysfunction after myocardial infarction. N Engl J Med 2003;348:1309-21.

13 McMurray JJ, Ostergren J, Swedberg K, Granger CB et al. Effects of candesartan in patients with chronic heart failure and reduced left-ventricular systolic function taking angiotensin-converting-enzyme inhibitors: the CHARM-Added trial. Lancet 2003;362:767-71.

14 Cohn JN, Johnson G, Ziesche S, Cobb F et al. A comparison of enalapril with hydralazine-isosorbide dinitrate in the treatment of patients with chronic congestive heart failure. N Engl J Med 1991;325: 303-10.

15 Cohn JN, Archibald DG, Ziesche S, Franciosa JA et al. Effect of vasodilator therapy on mortality in chronic congestive heart failure: Results of a Veterans Administration Cooperative Study. N Engl J Med 1986;314:1547-52.

16 Neuberg GW, Miller AB, O'Connor CM, Belkin R et al. Diuretic resistance predicts mortality in patients with advanced heart failure. Am Heart J 2002;144:31-8.

17 Batin P, Wickens M, McEntegart D, Fullwood L, Cowley AJ. The importance of abnormalities of liver function tests in predicting mortality in chronic heart failure. Eur Heart J 1995;16:1613-8.

18 The effect of digoxin on mortality and morbidity in patients with heart failure. The Digitalis Investigation Group. N Engl J Med 1997;336:525-33.

19 Packer M, Gheorghiade M, Young JB,
Costantini PJ et al. Withdrawal of digoxin from patients with chronic heart failure treated with angiotensin-convertingenzyme inhibitors. RADIANCE Study. N Engl J Med 1993; 329:1-7.

20 Rathore SS, Wang Y, Krumholz HM. Sex-based differences in the effect of digoxin for the treatment of heart failure. $N$ Engl $J$ Med 2002;347:1403-11.

21 Rathore SS, Curtis JP, Wang Y, Bristow MR, Krumholz HM. Association of serum digoxin concentration and outcomes in patients with heart failure. JAMA 2003; 289:871-8.

22 Anker SD, Clark AL, Kilowski C, Zugck C et al. Statins and survival in $2068 \mathrm{CHF}$ patients with ischemic and non-ischemic etiology. Circulation 2002;106:2535A.

23 Struthers AD, Donnan PT, Lindsay P, McNaughton D et al. Effect of allopurinol on mortality and hospitalisations in chronic heart failure: a retrospective cohort study. Heart 2002;87:229-34.

24 Ezekowitz JA, McAlister FA, Armstrong PW. Anemia is common in heart failure and is associated with poor outcomes: insights from a cohort of 12065 patients with new-onset heart failure. Circulation 2003; 107:223-5.

25 Silverberg DS, Wexler D, Sheps D, Blum M et al. The effect of correction of mild anemia in severe, resistant congestive heart failure using subcutaneous erythropoietin and intravenous iron: a randomized controlled study. J Am Coll Cardiol 2001;37:1775-80.

26 Guillo P, Mansourati J, Maheu B, Etienne Y et al. Long-term prognosis in patients with alcoholic cardiomyopathy and severe heart failure after total abstinence. Am J Cardiol 1997;79:1276-8.

27 Belardinelli R, Georgiou D, Cianci G, Purcaro A. Randomized, controlled trial of long-term moderate exercise training in chronic heart failure: effects on functional capacity, quality of life, and clinical outcome. Circulation 1999;99:1173-82.

28 Opasich C, Febo O, Riccardi PG, Traversi E et al. Concomitant factors of decompensation in chronic heart failure. Am J Cardiol 1996;78:354-7.

29 Moss AJ, Zareba W, Hall WJ, Klein $\mathrm{H}$ et al. Prophylactic implantation of a defibrillator in patients with myocardial infarction and reduced ejection fraction. $N$ Engl $J$ Med 2002;346:877-83.

30 Cleland JG, Daubert JC, Erdmann E, Freemantle $\mathrm{N}$ et al. The CARE-HF study (CArdiac REsynchronisation in Heart Failure study): rationale, design and end-points. Eur J Heart Fail 2001;3:481-9.

31 Feldman AM, Bristow MR. The Comparison of Medical Therapy, Pacing, and Defibrillation in Chronic Heart Failure (COMPANION) trial. Am Coll Cardiol 2003; Scientific Sessions.

32 Aaronson KD, Patel H, Pagani FD. Patient selection for left ventricular assist device 
therapy. Review. Ann Thorac Surg 2003; 75(6 Suppl):S29-35.

33 Hosenpud JD, Bennett LE, Keck BM, Boucek MM, Novick RJ. The Registry of the International Society for Heart and Lung Transplantation: seventeenth official report-2000. J Heart Lung Transplant 2000; 19:909-31.

\section{Suggested further reading}

1 SIGN Guideline 35: Diagnosis and treatment of heart failure due to left ventricular systolic dysfunction. Available on: http://www.sign.ac.uk/guidelines/fulltext/35/index.html

2 NICE Guideline. Chronic heart failure: Management of chronic heart failure in adults in primary and secondary care. Available from: http://www.nice.org.uk/

3 Remme WJ, Swedberg K; Task Force for the Diagnosis and Treatment of Chronic Heart Failure, European Society of Cardiology. Guidelines for the diagnosis and treatment of chronic heart failure. Eur Heart J 2001; 22:1527-60.

\section{Atrial fibrillation:}

\section{current perspectives}

Mark J Earley MRCP, Clinical Research

Fellow, Department of Cardiology,

St Bartholomew's Hospital, London

Simon C Sporton MD MRCP, Consultant Cardiologist, UCLH NHS Trust,

The Heart Hospital, London

Clin Med 2004;4:22-26

Dramatic advances in basic and clinical cardiac electrophysiology have rendered many arrhythmias amenable to cure by catheter ablation and have relegated anti-arrhythmic drugs to a subsidiary role. Unfortunately, however, the commonest sustained cardiac arrhythmia, atrial fibrillation (AF), remains incompletely understood and consequently difficult to manage. Nevertheless, important advances in our knowledge have recently been made; these will be reviewed in this article.

\section{Classification}

AF incorporates a range of subsets of which the mechanism and response to therapeutic intervention vary. A consensus on nomenclature has recently been achieved in an attempt to ensure appropriate management: ${ }^{1}$

- An AF event is either the first detected or a recurrent episode.

- Paroxysmal AF describes episodes that terminate spontaneously within seven days. longer than seven days or requires cardioversion by any means to restore sinus rhythm.

- Permanent AF is the term used when cardioversion has failed or has not been attempted.

\section{Mechanisms}

\section{Arrhythmias}

The mechanism of virtually all tachyarrhythmias can be described as:

- re-entrant, where wavefronts of electrical activation propagate continuously around lines of electrical conduction block, or

- focal, where activation wavefronts spread from a discrete source of repetitive electrical discharge.

AF, however, consists of multiple, irregular, constantly varying wavefronts that cannot be easily analysed under physiological conditions in the human heart. As a consequence, much of our understanding has come from experimental studies in animal models and
- $\mathrm{AF}$ is termed persistent if it lasts

\section{Key Points}

The ECG appearance of atrial fibrillation (AF) may result from different arrhythmia mechanisms

Electrical and structural remodelling are increasingly recognised as important influences on the natural history of AF and represent novel therapeutic targets

All patients with AF should be considered for anticoagulation with warfarin, depending on their stroke risk

Recent studies have failed to demonstrate an advantage of anti-arrhythmic drugs over palliation by ventricular rate control

Catheter ablation of the atrioventricular node is safe and gives good symptom relief when ventricular rate control cannot be achieved with drugs

Curative catheter ablation by pulmonary vein isolation is gaining popularity although numerous questions remain about the technique

KEY WORDS: atrial fibrillation, CPD, curative therapies, mechanisms, review 